\title{
Vasopressors and Inotropes in Acute Myocardial Infarction Related Cardiogenic Shock: A Systematic Review and Meta-Analysis
}

\author{
Mina Karami ${ }^{1,+}{ }^{(D}$, Veemal V. Hemradj ${ }^{2,+}{ }^{,}$Dagmar M. Ouweneel ${ }^{1}$, Corstiaan A. den Uil ${ }^{3}(\mathbb{D}$, \\ Jacqueline Limpens ${ }^{4}$, Luuk C. Otterspoor ${ }^{5}$, Alexander P. Vlaar ${ }^{6}{ }^{\mathbb{D}}$, Wim K. Lagrand ${ }^{6}$ and \\ José P. S. Henriques ${ }^{1, *(\mathbb{D})}$ \\ 1 Heart Center, Department of Interventional Cardiology, Amsterdam Cardiovascular Sciences, \\ Amsterdam UMC, University of Amsterdam, 1105 AZ Amsterdam, The Netherlands; \\ m.karami@amsterdamumc.nl (M.K.); d.m.ouweneel@amsterdamumc.nl (D.M.O.) \\ Department of Cardiology, Isala, 8025 AB Zwolle, The Netherlands; v.v.hemradj@amsterdamumc.nl \\ 3 Departments of Cardiology and Intensive Care Medicine, Erasmus MC, University Medical Center, \\ 3015 GD Rotterdam, The Netherlands; c.denuil@erasmusmc.nl \\ 4 Medical Library, Amsterdam UMC, University of Amsterdam, 1105 AZ Amsterdam, The Netherlands; \\ j.m.limpens@amsterdamumc.nl \\ 5 Heart Center Catharina Hospital, 5623 EJ Eindhoven, The Netherlands; otterspoor@gmail.com \\ 6 Department of Intensive Care, Amsterdam UMC, University of Amsterdam, 1105 AZ Amsterdam, \\ The Netherlands; a.p.vlaar@amsterdamumc.nl (A.P.V.); w.k.lagrand@amsterdamumc.nl (W.K.L.) \\ * Correspondence: j.p.henriques@amsterdamumc.nl \\ + These two authors contributed equally.
}

Received: 5 May 2020; Accepted: 25 June 2020; Published: 30 June 2020

\begin{abstract}
Vasopressors and inotropes are routinely used in acute myocardial infarction (AMI) related cardiogenic shock (CS) to improve hemodynamics. We aimed to investigate the effect of routinely used vasopressor and inotropes on mortality in AMI related CS. A systematic search of MEDLINE, EMBASE and CENTRAL was performed up to 20 February 2019. Randomized and observational studies reporting mortality of AMI related CS patients were included. At least one group should have received the vasopressor/inotrope compared with a control group not exposed to the vasopressor/inotrope. Exclusion criteria were case reports, correspondence and studies including only post-cardiac surgery patients. In total, 19 studies (6 RCTs) were included, comprising 2478 CS patients. The overall quality of evidence was graded low. Treatment with adrenaline, noradrenaline, vasopressin, milrinone, levosimendan, dobutamine or dopamine was not associated with a difference in mortality between therapy and control group. We found a trend toward better outcome with levosimendan, compared with control (RR $0.69,95 \%$ CI 0.47-1.00). In conclusion, we found insufficient evidence that routinely used vasopressors and inotropes are associated with reduced mortality in patients with AMI related CS. Considering the limited evidence, this study emphasizes the need for randomized trials with appropriate endpoints and methodology.
\end{abstract}

Keywords: cardiogenic shock; inotrope; vasopressor; myocardial infarction; low cardiac output; shock; review

\section{Introduction}

Cardiogenic shock (CS) is a low cardiac output state that leads to hypoperfusion and subsequent multi-organ failure with high mortality rates $[1,2]$. The commonly used clinical definition of CS is based on hemodynamic criteria and signs of hypoperfusion [3]. 
Vasopressors and inotropes are routinely used in the treatment of CS to improve hemodynamics and restore organ perfusion. Scientific statements recommend noradrenaline as the first-line pharmacologic treatment strategy in CS, with the addition of inotropes in patients with persistent low cardiac output $[4,5]$.

Acute myocardial infarction (AMI) is a common cause of CS, accounting for at least $30 \%$ of the cases [6-8]. Vasopressors and inotropes are used in patients with AMI related CS, in the assumption that they improve and maintain adequate coronary perfusion and cardiac output. However, these drugs are also associated with arrhythmias and may increase the myocardial oxygen demand by increasing the contractility, afterload and/or by reducing coronary perfusion [9].

Therefore, we performed a systematic review to examine the current evidence on the effect of different vasopressors and inotropes on mortality in patients with AMI related CS.

In this systematic review and meta-analysis, we addressed the following questions: (1) Is treatment with adrenaline, noradrenaline, vasopressin, milrinone, levosimendan, dobutamine or dopamine associated with reduced mortality in patients with AMI related CS? and (2) What is the effect of these drugs on complications and safety outcomes (e.g., duration of supportive measures, length of intensive care unit (ICU) stay, hemodynamic effects, organ failure and therapy-related complications)?

\section{Experimental Section}

This study followed the Preferred Reporting Items for Systematic Reviews and Meta-Analysis PRISMA guidelines. [10] The protocol was registered in the PROSPERO database (CRD42018107644).

\subsection{Selection Criteria}

To qualify for inclusion, studies must have reported on mortality in CS patients and include patients with AMI. Furthermore, studies were considered for inclusion if outcome data were reported in (A) patients treated with an inotrope or vasopressor and (B) a control group that was not exposed to the (same) inotrope or vasopressor therapy. The following inotropes and vasopressors were included: (1) adrenaline, (2) noradrenaline, (3) vasopressin, (4) milrinone, (5) levosimendan, (6) dobutamine and (7) dopamine. Studies comparing different dosages of inotropes or vasopressors were excluded, unless an unexposed control arm (B) was present. We excluded studies that reported only on post-cardiac surgery patients. We expected very few evidences from randomized controlled trials (RCTs) and therefore we included all study designs except case reports and correspondences.

\subsection{Search Strategy}

A medical information specialist (JL) conducted a systematic search of the following databases: MEDLINE (OVID), EMBASE (OVID), and the Cochrane Central Register of Controlled Trials (CENTRAL) from inception to 20 February 2019. The search included both controlled terms (i.e., MeSH-terms) and free-text words for: (1) cardiogenic shock (or shock /low cardiac output and MI) and (2) inotrope/vasopressor drugs (see Appendix A). Non-human studies, narrative reviews and editorials were excluded. No further restrictions were applied. Reference lists and citing articles of identified relevant papers were crosschecked. The search was adapted in the case of additional relevant studies. The bibliographic records retrieved were imported using EndNote X8 and duplications were removed.

\subsection{Data Extraction and Quality Assessment}

Two researchers (either MK, WL, DO or VH) independently screened titles and abstracts of the retrieved papers and excluded studies based on the selection criteria. Subsequently, two researchers independently assessed the eligibility of the potentially eligible papers in full text. Conference papers were considered for inclusion if they met selection criteria and necessary data were available. After the eligible studies were identified, two researchers $(\mathrm{MK}$ and $\mathrm{VH}$ ) independently performed data extraction. We attempted to retrieve unclear or missing data by contacting the corresponding authors of studies. 
The quality of the individual studies was assessed using the Revised Cochrane risk-of-bias (RoB 2.0) for RCTs and the Newcastle-Ottawa scale (assessed on mortality outcome level) for non-randomized studies [11,12]. The overall quality of evidence was assessed using the GRADE's approach [13]. Any discrepancies between the researchers were solved by discussion and/or the involvement of a third researcher $(\mathrm{JH})$.

\subsection{Data Analysis}

The primary outcome was mortality, defined as short-term ( $<90$ day) and long-term ( $\geq 90$ day) mortality. The therapy group was defined as the examined vasopressor/inotrope. The control group was constructed from the cumulated comparator of the different studies. We summarized mortality in a quantitative manner, using a random-effects model, presented with relative risks (RR) and 95\% confidence intervals (CI). Heterogeneity was evaluated using Chi-squared and I-squared test, with the significance set at a $p$-value of 0.10 . An I-squared test of $>40 \%$ was considered indication of substantial heterogeneity. Sensitivity analyses (excluding conference papers and/or observational studies) were applied where appropriate. Review Manager (version 5.3) was used for statistical analysis. We also provided a narrative synthesis of the included studies regarding study population, therapies and outcome(s) and described the following secondary outcomes: duration of supportive measures, length of ICU stay, hemodynamic effects, organ failure and therapy-related complications.

\section{Results}

\subsection{Search Results}

Of the 6187 unique publications retrieved, 110 were assessed full text for eligibility and 19 studies were included in the review. The reasons for exclusion are listed in Figure 1.

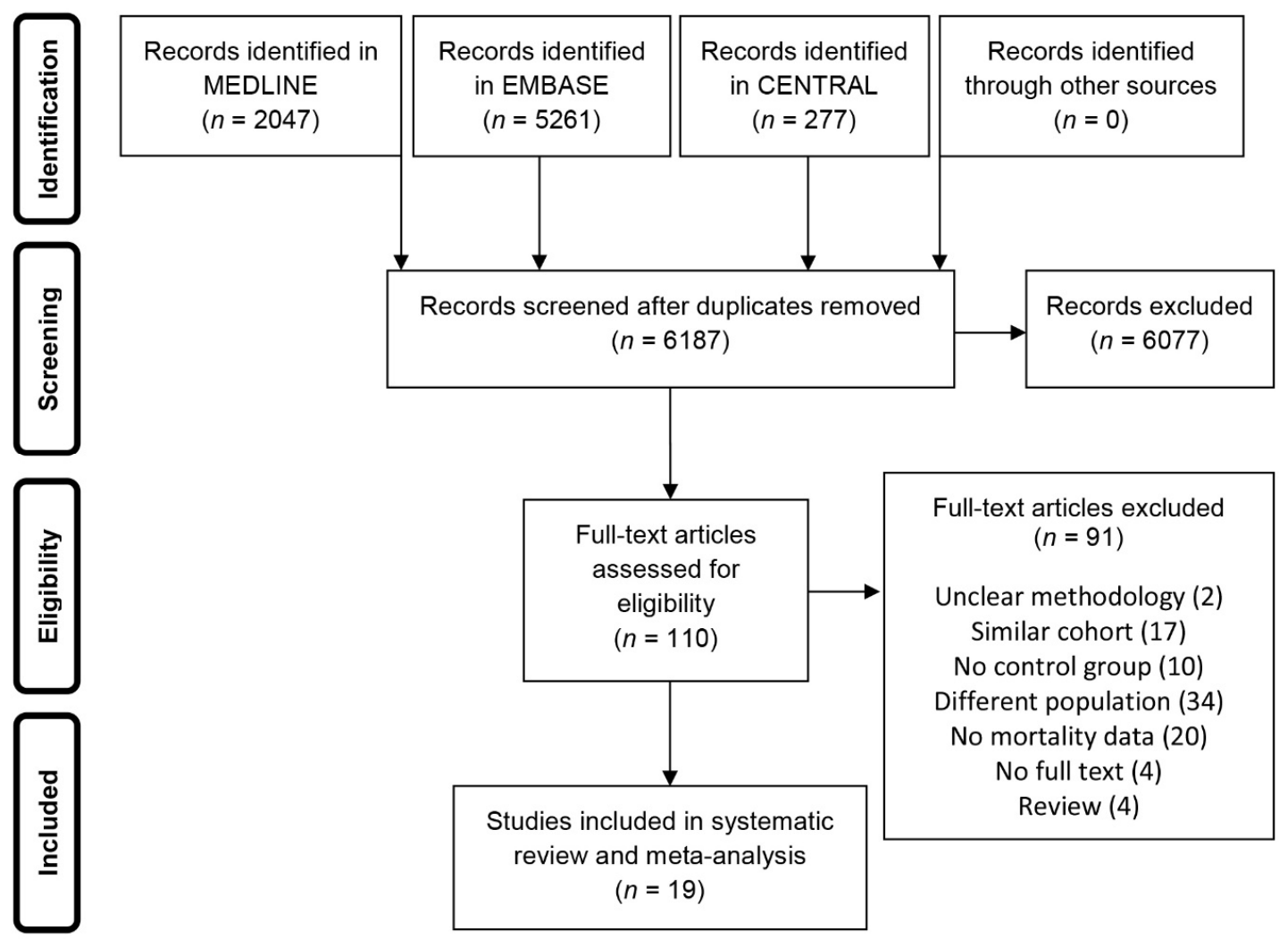

Figure 1. Flowchart of study selection. 


\subsection{Study Characteristics}

Study characteristics of the 19 included studies are presented in Table 1.

Table 1. Summary of included studies $(n=19)$ on inotrope/vasopressor therapy in cardiogenic shock.

\begin{tabular}{ccccccccc}
\hline Study & Year & Country & Center & Setting & Inclusion Period & Follow-up & Overall N & CS N \\
\hline Cronin & 1965 & Canada & Single & Retrospective cohort & $1952-1961$ & 10 years & 140 & 140 \\
\hline Moulopoulos & 1993 & Greece & Single & Retrospective cohort & $1978-1991$ & 1 month & 55 & 55 \\
\hline Andriange & 1971 & Belgium & Single & Retrospective cohort & $1967-1970$ & 1 year & 450 & 45 \\
\hline Samimi-Fard & 2007 & Spain & Single & Randomized trial & $2003-2004$ & 1 year & 22 & 22 \\
\hline El Mokhtari & 2007 & Germany & Single & Retrospective cohort & - & 1 year & 20 & 20 \\
\hline Fuhrmann & 2008 & Germany & Single & Randomized trial & $2003-2005$ & 30 days & 32 & 32 \\
\hline Myburgh & 2008 & Australia & Multi & Randomized trial & $2004-2006$ & 90 days & 280 & 128 \\
\hline Christoph & 2008 & Germany & Single & Prospective cohort & $2003-2005$ & - & 22 & 22 \\
\hline De Backer & 2010 & Belgium & Multi & Randomized trial & $2003-2007$ & 1 year & 1679 & 280 \\
\hline Omerovic & 2010 & Sweden & Single & Prospective cohort & $2004-2006$ & 1 year & 94 & 94 \\
\hline Caetano & 2012 & Portugal & - & $\begin{array}{c}\text { Retrospective cohort } \\
\text { (conference paper) }\end{array}$ & - & $10.6 \pm 10.9$ & 37 & 37 \\
\hline Huseby & 2013 & Norway & Single & Randomized trial & $2006-2010$ & 6 months & 61 & 9 \\
\hline Affronti & 2013 & Italy & Single & $\begin{array}{c}\text { Retrospective } \\
\text { case-control }\end{array}$ & 2011 & - & 17 & 17 \\
\hline Katsytadze & 2013 & \multirow{2}{*}{ Ukraine } & - & $\begin{array}{c}\text { Retrospective cohort } \\
\text { (conference paper) }\end{array}$ & - & 1 year & 27 & 27 \\
\hline Yagi & 2015 & Japan & Multi & $\begin{array}{c}\text { Prospective cohort } \\
\text { (conference paper) }\end{array}$ & $2012-2014$ & 30 days & 979 & 240 \\
\hline Tarvasmaki & 2016 & Finland & Multi & Prospective cohort & $2010-2012$ & 90 days & 216 & 216 \\
\hline Levy & 2018 & France & Multi & Randomized trial & $2011-2016$ & 60 days & 57 & 57 \\
\hline Vally & 2019 & France & Single & Retrospective cohort & $2010-2017$ & 30 days & 150 & 150 \\
\hline Lewis & 2018 & USA & Single & Retrospective cohort & $2013-2015$ & In-hospital & 100 & 100 \\
\hline & & & & & & \\
\hline
\end{tabular}

CS: cardiogenic shock.

\subsection{Participants}

The overall patient population included in the studies and baseline characteristics of the CS patients are described in the Supplementary Materials, Table S1. In total, 4441 patients were included, of whom 2478 CS patients. All included studies included at least a subgroup with AMI related CS, and 10 studies included only patients with AMI related CS. Overall, there were 137 CS patients treated with adrenaline, 594 CS patients treated with noradrenaline, 8 CS patients treated with vasopressin, 50 CS patients treated with milrinone, 209 CS patients treated with levosimendan, 200 CS patients treated with dobutamine and 367 CS patients treated with dopamine.

\subsection{Intervention}

Criteria for initiation of vasopressor or inotrope therapy differed amongst the various studies and are described in the Supplementary Materials (Table S1).

\subsection{Comparison}

We identified six RCTs with different comparisons [14-19]; noradrenaline versus adrenaline in patients with AMI related CS (Levy, 2018), noradrenaline versus adrenaline in patients that required a vasopressor for any cause (Myburgh, 2008), noradrenaline versus dopamine in patients with shock of all-causes (De Backer, $2010=$ SOAP II trial), dobutamine versus levosimendan in STEMI patients with CS after PCI (Samimi-Fard, 2007), levosimendan versus placebo in acute STEMI patients with clinical signs of heart failure $<48 \mathrm{~h}$ after primary PCI (Huseby, $2013=$ LEAF trial) and levosimendan versus enoximone in patients with refractory CS $<2 \mathrm{~h}$ after PCI (Fuhrmann, 2008). Of note, in all of the 
included studies, the control group was exposed to some type of vasopressor or inotrope other than the drug that was examined (noradrenaline in most cases).

\subsection{Quality of Studies}

The overall body of evidence regarding the primary outcome was graded low, assessed using the GRADE's approach. This grade was based on only limited evidence from randomized trials with serious inconsistency and risk of bias. The individual quality assessment of the studies is presented in the Supplementary Materials; Table S2 for the randomized studies and Table S3 for the observational studies.

\subsection{Mortality Outcomes}

The synthesis of mortality is shown in Figure 2 for short-term mortality and Figure 3 for long-term mortality. Mortality outcomes of CS patients in the individual studies are described in the Supplementary Materials, Table S4.

\subsubsection{Adrenaline vs. Constructed Control}

Three of the included studies reported on patients treated with adrenaline $[14,15,20]$. Levy et al. and Myburgh et al. performed an RCT comparing the effect of adrenaline and noradrenaline on hemodynamic parameters (respectively, cardiac index evolution and achievement of MAP goal $>24 \mathrm{~h}$ ). Tarvasmaki et al. performed an observational study in which they compared 90-day mortality of patients with acute CS treated with adrenaline (also for noradrenaline, vasopressin, levosimendan, dobutamine, dopamine) versus a non-exposed control group. The two RCTs comparing adrenaline with noradrenaline evaluated 28-day mortality. Their pooled estimate showed no treatment effect of adrenaline on short-term mortality (RR $1.22,95 \%$ CI $0.60-2.50$, heterogeneity $I^{2}=58 \%$ ). Pooled estimate of the studies that reported on long-term mortality also showed no treatment effect of adrenaline (RR $1.3795 \%$ CI $0.45-4.16 ; n=2$ studies), with substantial heterogeneity between the studies $\left(I^{2}=\right.$ 94\%).

\subsubsection{Noradrenaline vs. Constructed Control}

Six studies (three RCTs) reported on patients treated with noradrenaline [14-16,20-22]. Treatment with noradrenaline was not associated with a difference in short-term mortality (RR $0.84,95 \%$ CI $0.63-1.10 ; n=4$ studies, heterogeneity $I^{2}=30 \%$ ). Sensitivity analysis including only the three RCTs that reported on short-term mortality also showed no treatment effect of noradrenaline (RR $0.77,95 \%$ CI $0.56-1.06 ; I^{2}=26 \%$ ). Likewise, the pooled estimate showed no treatment effect of noradrenaline on long-term mortality (RR 1.31, 95\% CI 0.80-2.15; $n=3$ studies), with substantial heterogeneity between the studies $\left(I^{2}=81 \%\right)$. 
Risk Ratio Therapy Control

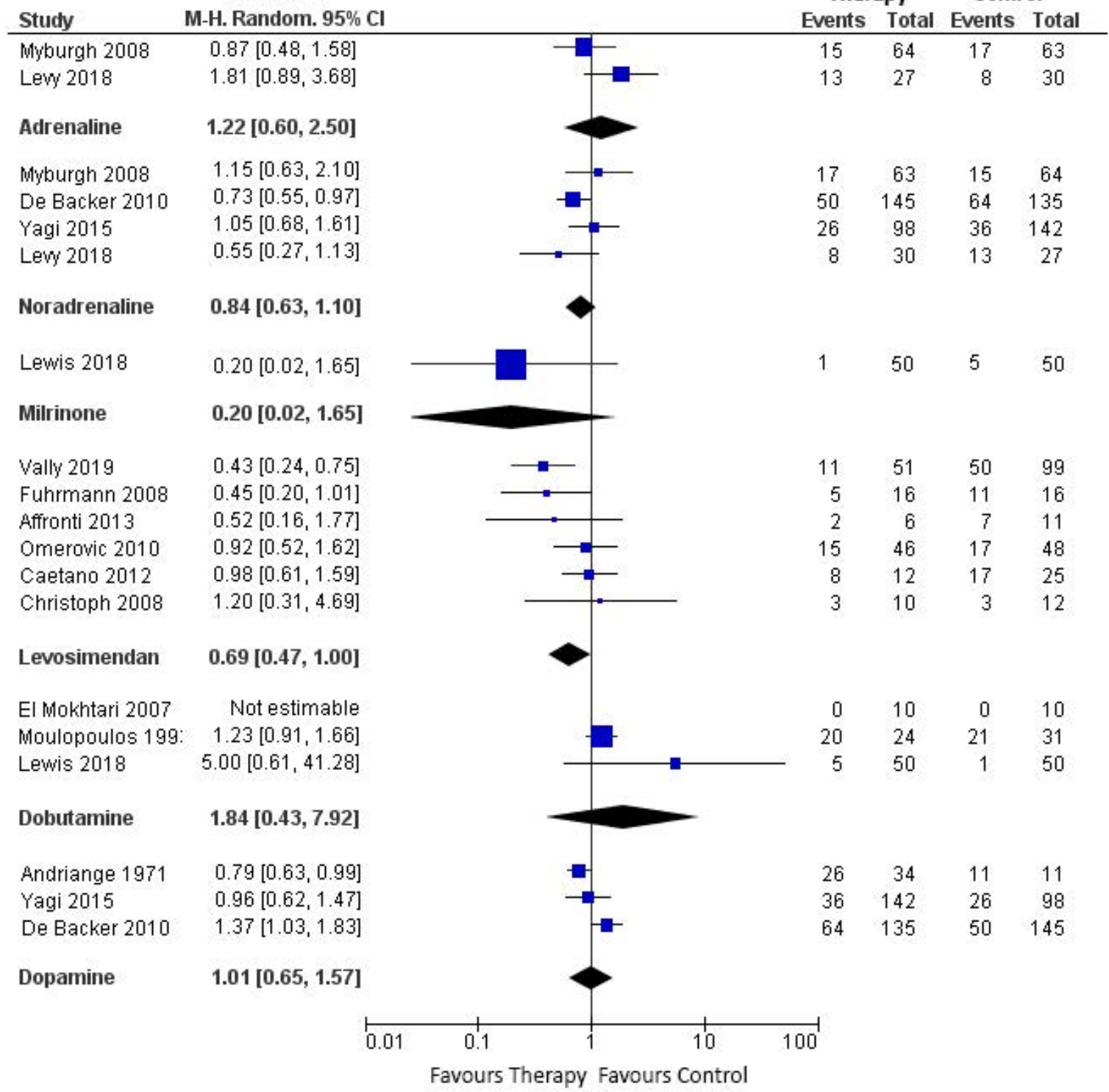

Figure 2. Forest plot demonstrating short-term ( $<90$ day) mortality of cardiogenic shock patients treated with a vasopressor/inotrope versus a constructed control group. 


\begin{tabular}{|c|c|c|c|c|c|c|c|}
\hline \multirow{3}{*}{\multicolumn{2}{|c|}{$\begin{array}{lc}\text { Study } & \begin{array}{c}\text { Risk Ratio } \\
\text { M-H, Random, 95\% Cl }\end{array} \\
\text { Myburgh 2008 } & 0.79[0.49,1.26]\end{array}$}} & & & \multicolumn{2}{|c|}{ Therapy } & \multicolumn{2}{|c|}{ Control } \\
\hline & & & & Events & Total & Events & Total \\
\hline & & & & 20 & 62 & 25 & 61 \\
\hline Tarvasmaki 2016 & $2.33[1.76,3.08]$ & & & 34 & 46 & 54 & 170 \\
\hline Adrenaline & $1.37[0.45,4.16]$ & & & & & & \\
\hline Cronin 1965 & $1.01[0.86,1.19]$ & & & 79 & 95 & 37 & 45 \\
\hline Myburgh 2008 & $1.27[0.79,2.03]$ & & - & 25 & 61 & 20 & 62 \\
\hline Tarvasmaki 2016 & $1.95[1.18,3.22]$ & & & 76 & 162 & 13 & 54 \\
\hline Noradrenaline & $1.31[0.80,2.15]$ & & & & & & \\
\hline Tarvasmaki 2016 & $2.25[1.64,3.07]$ & & & 7 & 8 & 81 & 208 \\
\hline Vasopressin & $2.25[1.64,3.07]$ & & & & & & \\
\hline Katsytadze 2013 & $0.63[0.25,1.58]$ & & & 4 & 12 & 8 & 15 \\
\hline Husebye 2013 & $0.63[0.08,4.66]$ & & & 1 & 4 & 2 & 5 \\
\hline Tarvasmaki 2016 & $0.74[0.49,1.14]$ & & & 17 & 52 & 72 & 164 \\
\hline Omerovic 2010 & $1.23[0.74,2.03]$ & & & 20 & 46 & 17 & 48 \\
\hline Samimi-Fard 2007 & $3.00[0.37,24.58]$ & & & 3 & 11 & 1 & 11 \\
\hline Levosimendan & $0.90[0.65,1.23]$ & & & & & & \\
\hline Samimi-Fard 2007 & $0.33[0.04,2.73]$ & & & 1 & 11 & 3 & 11 \\
\hline El Mokhtari 2007 & $0.75[0.22,2.52]$ & & & 3 & 10 & 4 & 10 \\
\hline Tarvasmaki 2016 & $1.36[0.98,1.87]$ & & & 50 & 105 & 39 & 111 \\
\hline Dobutamine & $1.13[0.66,1.93]$ & & & & & & \\
\hline Andriange 1971 & $0.93[0.78,1.10]$ & & & 27 & 30 & 11 & 11 \\
\hline Tarvasmaki 2016 & $1.02[0.72,1.46]$ & & & 24 & 56 & 67 & 160 \\
\hline Dopamine & $0.94[0.81,1.10]$ & & & & & & \\
\hline & 0.01 & $\begin{array}{c}0.1 \\
\text { avours Therapy }\end{array}$ & $\begin{array}{cc}10 \\
\text { Favours Control }\end{array}$ & $\overrightarrow{100}$ & & & \\
\hline
\end{tabular}

Figure 3. Forest plot demonstrating long-term ( $\geq 90$ day) mortality of cardiogenic shock patients treated with a vasopressor/inotrope versus a constructed control group.

\subsubsection{Vasopressin vs. Constructed Control}

Mortality outcomes of vasopressin treatment were available in one observational study [20]. In this study 90 day mortality consisted of 7 deaths out of 8 patients $(87.5 \%)$ treated with vasopressin, compared with 81 deaths out of 208 patients (38.9\%) in the control group (RR 2.25, 95\% CI 1.64-3.07).

\subsubsection{Milrinone vs. Constructed Control}

Mortality outcomes of milrinone treatment were available in one observational study [23]. Lewis showed no treatment effect of milrinone on in-hospital mortality, compared with dobutamine. There was 1 death out of 50 patients $(2.0 \%)$ treated with milrinone, compared with 5 deaths out of 50 patients $(10.0 \%)$ in the control group (RR $0.20,95 \%$ CI $0.02-1.65)$.

\subsubsection{Levosimendan vs. Constructed Control}

Ten studies (three RCTs) reported mortality outcomes of patients treated with levosimendan [17-20,24-29]. In six studies that reported on short-term mortality, the overall trend of the pooled estimate favored levosimendan therapy over the constructed control (RR $0.69,95 \%$ CI $0.47-1.00$; participants $=352$, heterogeneity $I^{2}=39 \%$ ). In sensitivity analysis excluding the conference paper, levosimendan was associated with favorable outcome, compared to the constructed control (RR 0.61, $95 \%$ CI $0.41-0.90, n=5$ studies). Pooled estimate showed no treatment effect of levosimendan on long-term mortality (RR $0.90,95 \%$ CI $0.65-1.23$; studies, $n=5$, with low heterogeneity $I^{2}=4 \%$ ). 
Sensitivity analysis including only the two RCTs that reported long-term mortality showed similar results (RR $0.78,95 \%$ CI $0.36-1.70 ; n=3$ studies). We also performed additional sensitivity analysis for long-term mortality excluding only the conference paper (RR 0.95 , 95\% CI $0.65-1.40, n=4$ studies).

\subsubsection{Dobutamine vs. Constructed Control}

Five studies (one RCT) reported on patients treated with dobutamine $[17,20,23,30,31]$. Pooled estimate showed no treatment effect of dobutamine on short-term mortality (RR 1.84, 95\% CI 0.43-7.92, substantial heterogeneity $I^{2}=56 \%$ ). Likewise, the pooled estimate of studies that reported on long-term mortality showed no treatment effect of dobutamine (RR1.13, 95\% CI 0.66-1.93; $n=3$ studies, low heterogeneity $I^{2}=19 \%$ ).

\subsubsection{Dopamine vs. Constructed Control}

Four studies (one RCT) reported on patients treated with dopamine [16,20,22,32]. Three studies (one RCT) reported short-term mortality. The pooled estimate showed no treatment effect of dopamine (RR $1.0195 \%$ CI $0.65-1.57$, substantial heterogeneity $I^{2}=84 \%$ ). Sensitivity analysis without the conference paper showed similar results (RR $1.04,95 \%$ CI $0.51-2.12 ; n=2$ studies). There was also no treatment effect of dopamine on long-term mortality (RR $0.94,95 \%$ CI $0.81-1.10 ; n=2$ studies, low heterogeneity $I^{2}=0 \%$ ).

\subsection{Secondary Outcomes}

We summarized the primary endpoint, results and secondary outcomes from the included studies in Table S5, Supplementary Materials. Data on adverse events and safety outcomes were not always available in the studies, but arrhythmic events were reported frequently.

\section{Discussion}

In the present article, we reviewed the current evidence on outcomes of vasopressors and inotropes in patients with AMI related CS and found that adrenaline, noradrenaline, milrinone, levosimendan, dobutamine and dopamine were not associated with a difference in short-term or long-term mortality. The quality of the evidence was low as studies were mostly observational, heterogeneous and included a small number of patients.

We found a positive trend in the pooled estimate of six studies reporting on short-term mortality toward treatment with levosimendan (RR $0.69,95 \%$ CI $0.47-1.00$, low-level of evidence). Vasopressin was associated with a difference in long-term mortality in favor of the control group. However, this was based on the results of one observational trial including 8 CS patients treated with vasopressin, compared with a much larger control group. These results are highly biased since the study had a small sample size, was non-randomized and did not adjust for baseline differences.

Our results extend a 2018 Cochrane review with a smaller size (including 13 RCTs; 2001 participants) [33]. The scope of this review was significantly different from ours, since the majority of the included patients had acute on chronic heart failure or cardiac surgery complicated by low cardiac output syndrome (LCOS) or CS, instead of AMI related CS. In this review the effect of inotropes and vasodilators on mortality in patients with LCOS or CS was evaluated, demonstrating low-quality evidence that suggested a short-term mortality benefit of levosimendan compared with dobutamine. None of the other examined inotropes or vasodilators were associated with differences in mortality.

Furthermore, a previous Cochrane review published in 2016, investigated vasopressor therapy for hypotensive shock of all etiologies (mostly septic patients) [34]. Again, in this review patients with AMI related CS were underrepresented and there was no subgroup analysis performed according to shock type. Although none of the vasopressors in this review was associated with a difference in mortality, dopamine significantly increased the risk for arrhythmias compared to noradrenaline. 
The ESC 2017 Guidelines for the management of AMI in patients presenting with ST-segment elevation recommend dobutamine as the initial therapy in predominant low cardiac output (Class IIb) [5]. Noradrenaline is recommended in CS and severe hypotension (Class IIb) based on one study (De Backer et al.) reporting a lower rate of arrhythmias and a trend toward lower mortality compared with dopamine in a subgroup analysis [16]. However, there are some methodological concerns regarding this trial since randomization was not stratified and the test for subgroup differences $(p=0.87)$ suggested that the effect was not significant. Also, the subgroup of CS patients was heterogeneous, consisting of AMI, chronic heart failure and post-cardiotomy patients. A recently published RCT examined reduced exposure to noradrenaline through permissive hypotension (lower MAP target) in patients with vasodilatory hypotension aged 65 year or older and found that reduced noradrenaline was not harmful and might even be beneficial [35].

Despite the lack in evidence showing efficacy of treatment with vasopressors and inotropes in AMI related CS, there is a widespread use in clinical practice. Physicians are unlikely to refrain from the use of any vasopressor or inotrope in patients with CS. Of note, none of the included studies in this review had a control group that did not receive any vasopressor or inotrope. Therefore, the current literature doesn't tell us much about the effectiveness of any agent vs. placebo but only against each other. In other words, these drugs are either equally effective or equally ineffective. Furthermore, it is important to realize that hemodynamic parameters do not necessarily correlate with tissue perfusion and patient outcomes. It has not been proven that hemodynamic improvement in CS patients results in better outcome. Currently, CS is a clinical diagnosis that has not been well defined, and there is significant heterogeneity in CS definition among the studies used for meta-analysis. Therefore, the current level of evidence is insufficient to draw conclusions on whether vasopressors/inotropes are effective. However, we do believe it is of clinical importance to review and summarize the current evidence regarding routinely used therapies. This systematic review and meta-analysis is the first to report outcomes of commonly used vasopressor/inotropic therapies in patients with CS complicating AMI.

The authors believe that rigorous studies exploring the efficacy of vasopressors and inotropes with appropriate endpoint and methodology are advocated. Not only to compare the efficacy between different drugs and dosages but also to ascertain whether these drugs are effective in reducing mortality. Several RCTs that challenged the current pharmacological treatment in patients with out-of-hospital cardiac arrest (OHCA) demonstrated that although the administration of adrenaline was associated with improved short-term survival in OHCA, it did not affect survival with favorable neurological outcome [36-38]. It is important to also initiate large placebo-controlled, double-blind, RCTs in CS patients to definitively establish the effect of pharmacological therapy. Studying the CS population in an RCT is challenging but feasible with the adoption of adequate methodology and statistical plan analysis.

In the present study, several decisions were made by the research team that could possibly limit our conclusion. The aim of this study was to summarize the evidence regarding vasopressor and inotropic treatment of a selected patient group (AMI related CS), since patients presenting with a non-hypotensive low-output status differ significantly in their treatment goal and strategy. Due to the limited number of studies exclusively reporting on patients with AMI related CS, we also included studies with mixed etiologies, as long as there were AMI patients included in the cohort.

Another limitation of our review was that the included studies were very heterogeneous in terms of participants, interventions, comparisons and outcomes. Specific subgroup analysis to reduce heterogeneity was not possible, due to the limited number of studies that were available regarding the different drugs. Moreover, single center, retrospective studies with a small sample size were included, which are likely to have significant selection bias. Furthermore, we included all study designs, without any publication or language restriction. It may be debatable to include conference papers (of which the methodological quality could not be properly assessed due to limited information). However, including conference papers may also reduce the effect of potential publication bias. Moreover, randomized evidence is very limited, and observational data is informative in 
assessing therapy-related complications and safety outcomes. To examine the best possible level of evidence, we performed sensitivity analyses where possible excluding the conference papers and/or observational studies.

\section{Conclusions}

There is insufficient evidence that routinely used vasopressors and inotropes are associated with reduced mortality in patients with AMI related CS. Considering the limited evidence, this study emphasizes the need for proper randomized trials.

Supplementary Materials: The following are available online at http://www.mdpi.com/2077-0383/9/7/2051/s1. Table S1: Overall patient population and baseline characteristics. Table S2: Quality assessment of the randomized trials. Table S3: Quality assessment of the observational studies. Table S4: Mortality outcomes for cardiogenic shock population. Table S5: Primary and secondary outcome(s) of the included studies.

Author Contributions: Conceptualization, D.M.O., W.K.L. and J.P.S.H.; data curation, M.K. and V.V.H.; formal analysis, M.K. and V.V.H.; methodology, M.K., V.V.H., D.M.O., W.K.L. and J.P.S.H.; resources, J.L.; supervision, J.P.S.H.; writing-original draft, M.K. and V.V.H.; writing-review and editing, C.A.d.U., L.C.O., A.P.V., W.K.L. and J.P.S.H. All authors have read and agreed to the published version of the manuscript.

Funding: This research received no external funding.

Conflicts of Interest: The authors declare no conflicts of interest.

\section{Appendix A Search strategies}

\section{Medline}

Database(s): Ovid MEDLINE(R) and Epub Ahead of Print, In-Process \& Other Non-Indexed Citations and Daily 1946 to February 19, 2019

Search Strategy: 2019-02-20

\begin{tabular}{|c|c|c|}
\hline \# & Searches & Results \\
\hline 1 & shock, cardiogenic/ & 7757 \\
\hline 2 & (cardiogen* adj9 shock*).tw,ot,kw,kf. & 10393 \\
\hline 3 & (circulator* adj3 shock*).tw,ot,kf. & 1251 \\
\hline 4 & coron $^{*}$ shock $^{*} . \mathrm{tw}, \mathrm{ot}, \mathrm{kw}, \mathrm{kf}$. & 20 \\
\hline 5 & acute circulatory fail ${ }^{*} . \mathrm{tw}, \mathrm{ot}, \mathrm{kw}$ & 247 \\
\hline 6 & $\begin{array}{l}\text { *shock/dt not (septic or sepsis or bacter*em* or infect* or endotoxin* or heat shock or HSP* or } \\
\text { anaphyl" or allergic or vasodilat" or osmotic or h?emorr* or bleeding or toxic or neurogen* or } \\
\text { burn" or shock-wave or shock-resistant or hypovolemic or electroconvuls* or distributive } \\
\text { shock*).ti. }\end{array}$ & 711 \\
\hline 7 & $\begin{array}{l}\text { ((undifferent* or undiagnos* or different or various or variety or type or types or kind or kinds } \\
\text { or forms or states or etiologies) adj2 }\left(\text { shock }^{*} \text { not heat shock }{ }^{*}\right) \text { ).tw. }\end{array}$ & 1662 \\
\hline 8 & or/1-7 [I = cardiogenic shock $]$ & 16778 \\
\hline 9 & $\begin{array}{l}\text { myocardial ischemia/ or acute coronary syndrome/ or exp myocardial infarction/ or } \\
\text { percutaneous coronary intervention/ or angioplasty, balloon, coronary/ or myocardial } \\
\text { revascularization/ or coronary artery bypass/ }\end{array}$ & 275348 \\
\hline 10 & $\begin{array}{l}\left(\left(\left(\text { myocard }{ }^{*} \text { or heart or card* or ST) adj3 }\left(\text { infarct }^{*} \text { or isch?em }{ }^{*}\right)\right) \text { or }(\text { coronary intervent* or STEMI }\right.\right. \\
\text { or PCI or angioplast* or post-isch* or postisch* or postinfarct* or post-infarct* or MI or AMI or } \\
\text { myocard* revasc* or coronary artery bypass* or CABG or aortocoronary bypass }{ }^{*} \text { or coronary } \\
\text { bypass*)).tw,ot,kf. }\end{array}$ & 379295 \\
\hline 11 & 9 or $10[\mathrm{MI}]$ & 454472 \\
\hline 12 & $\begin{array}{l}\text { (shock/ or shock.ti,kw.) not (electric countershock/ or (septic or sepsis or bacter*em* or infect* or } \\
\text { endotoxin* or heat shock or HSP* or anaphyl* or allergic or vasodilat* or osmotic or h?emorr* or } \\
\text { bleeding or toxic or neurogen* or burn* or shock-wave or shock-resistant or hypovolemic or } \\
\text { electroconvuls* or distributive shock*).ti.) [shock general] }\end{array}$ & 30283 \\
\hline 13 & cardiac output, low/ & 5447 \\
\hline 14 & $\begin{array}{l}\left(\left(\text { low }^{*} \text { or diminish }\right.\right. \\
\left.\text { output }{ }^{*}\right) . \mathrm{tw}, \mathrm{kf} \text {. }\end{array}$ & 8066 \\
\hline
\end{tabular}




\begin{tabular}{|c|c|c|}
\hline \# & Searches & Results \\
\hline 15 & 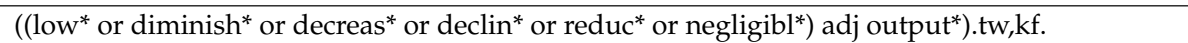 & 1988 \\
\hline 16 & cardiac output low.tw,kf,ot. & 51 \\
\hline 17 & (LCOS or COS or LCO).tw,ot,kw. & 17758 \\
\hline 18 & ((instab* or unstab*) adj1 h?emodyn*).tw,kf. & 7625 \\
\hline 19 & or/12-18 [shock, low CO] & 69271 \\
\hline 20 & 11 and $19[\mathrm{II}=\mathrm{MI}+\mathrm{CO}]$ & 8371 \\
\hline 21 & 8 or 20 [ I II ] & 20946 \\
\hline 22 & $\begin{array}{l}\text { (animals/ not humans/) or (porcine or piglet or pig or pigs or rat or rats or dogs or dog or } \\
\text { canine).ti. or ph?eochrom*.mp. }\end{array}$ & 4677715 \\
\hline 23 & $\begin{array}{l}\text { (review or editorial).pt. not ((case reports or clinical trial or clinical trial phase iii or clinical trial } \\
\text { phase iv or comparative study or controlled clinical trial or evaluation studies or letter or meta } \\
\text { analysis or randomized controlled trial).pt. or case-control studies/ or exp cohort studies/ or } \\
\text { cross-sectional studies/ or (systematic adj3 (literature or review)).tw,ot,kf.) }\end{array}$ & 2590121 \\
\hline 24 & 22 or 23 & 7115287 \\
\hline 25 & 21 not 24 [ I II - human not review,editorial] & 16394 \\
\hline 26 & cardiotonic agents/tu, ad & 8559 \\
\hline 27 & catecholamines/ad, tu & 948 \\
\hline 28 & (cardiotonic ${ }^{*}$ or inopressor ${ }^{*}$ or inodilator $\left.{ }^{*}\right) . t w, o t, k w$. & 2445 \\
\hline 29 & 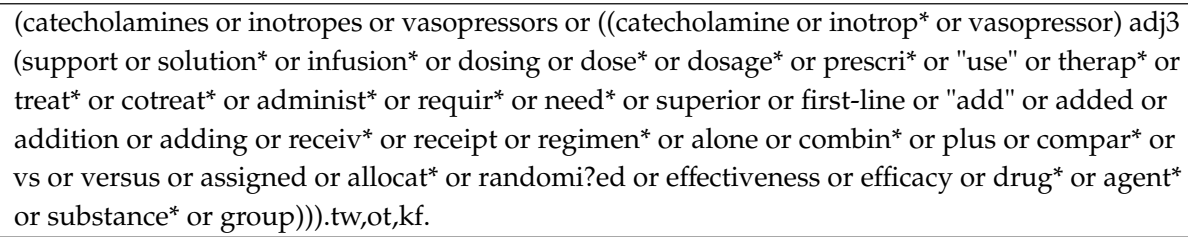 & 48357 \\
\hline 30 & dopamine/ & 67481 \\
\hline 31 & (dopamin* or hydroxytyramin* or Intropin*).tw,ot,kw. & 145939 \\
\hline 32 & dobutamine/ & 6002 \\
\hline 33 & dobutamin*.tw,ot,kw. & 8454 \\
\hline 34 & noradrenaline/ & 84076 \\
\hline 35 & (norepinephrin* or noradrenalin*).tw,ot,kw. & 92575 \\
\hline 36 & adrenaline/ & 54084 \\
\hline 37 & (epinephrin* or adrenalin*).tw,ot,kw. & 56754 \\
\hline 38 & milrinone/ & 1316 \\
\hline 39 & milrinon*.tw,ot,kw. & 1847 \\
\hline 40 & vasopressins/ & 21322 \\
\hline 41 & vasopressin*.tw,ot,kw. & 33741 \\
\hline 42 & simendan/ & 1042 \\
\hline 43 & (simendan or levosimend*).tw,ot,kw. & 1286 \\
\hline 44 & or/26-43 [ inotropes/vasopressors ] & 378001 \\
\hline 45 & 25 and 44 [ cardiogenic shock + inotropes/vasopressors ] & 2050 \\
\hline 46 & remove duplicates from 45 [ cardiogenic shock + inotropes/vasopressors -deduplicated ] & 2047 \\
\hline
\end{tabular}

\section{Embase}

Database(s): Embase Classic+Embase 1947 to 2019 February 19

Search Strategy: 2019-02-20

\begin{tabular}{|c|c|c|}
\hline \# & Searches & Results \\
\hline 1 & cardiogenic shock/ & 24059 \\
\hline 2 & (cardiogen* adj9 shock*).tw,ot,kw. & 18652 \\
\hline 3 & (circulator ${ }^{*}$ adj3 shock*).tw,ot,kw. & 1949 \\
\hline 4 & coron $^{*}$ shock$^{*} . \mathrm{tw}, \mathrm{ot}, \mathrm{kw}$ & 32 \\
\hline 5 & acute circulatory fail*.tw,ot,kw. & 465 \\
\hline 6 & $\begin{array}{l}\text { *Shock/dt not (septic or sepsis or bacter*em* or infect* or endotoxin* or heat shock or HSP* or } \\
\text { anaphyl* or allergic or vasodilat* or osmotic or h?emorr* or bleeding or toxic or neurogen* or } \\
\text { burn* or shock-wave or shock-resistant or hypovolemic or electroconvuls* or distributive } \\
\text { shock }{ }^{*} \text { ).ti. }\end{array}$ & 1157 \\
\hline
\end{tabular}




\begin{tabular}{|c|c|c|}
\hline \# & Searches & Results \\
\hline 7 & $\begin{array}{l}\text { ((undifferent* or undiagnos* or different or various or variety or type or types or kind or kinds } \\
\left.\text { or forms or states or etiologies) adj2 (shock* not heat shock }{ }^{*}\right) \text { ).tw. }\end{array}$ & 2735 \\
\hline 8 & or/1-7 [ I ] & 32877 \\
\hline 9 & $\begin{array}{l}\text { heart muscle ischemia/ or heart infarction/ or acute heart infarction/ or anterior myocardial } \\
\text { infarction/ or heart infarction size/ or exp heart ventricle infarction/ or non st segment elevation } \\
\text { myocardial infarction/ or posterior myocardial infarction/ or st segment elevation myocardial } \\
\text { infarction/ or exp percutaneous coronary intervention/ or percutaneous transluminal } \\
\text { angioplasty/ or coronary artery bypass graft/ or coronary artery bypass surgery/ }\end{array}$ & 547773 \\
\hline 10 & 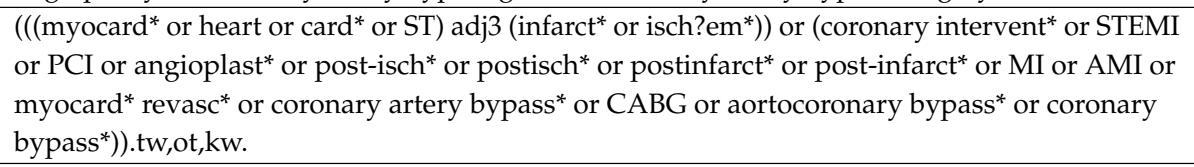 & 572593 \\
\hline 11 & 9 or $10[\mathrm{MI}]$ & 737611 \\
\hline 12 & $\begin{array}{l}\text { (*shock/ or shock.ti.) not (exp heart stimulation/ or (septic or sepsis or bacter*em* or infect }{ }^{*} \text { or } \\
\text { endotoxin* or heat shock or HSP* or anaphyl }{ }^{*} \text { or allergic or vasodilat* or osmotic or h?emorr* or } \\
\text { bleeding or toxic or neurogen* or burn* or shock-wave or shock-resistant or hypovolemic or } \\
\text { electroconvuls* or distributive shock*).ti.) [shock general] }\end{array}$ & 32315 \\
\hline 13 & forward heart failure/ & 5518 \\
\hline 14 & $\begin{array}{l}\left(\left(\text { low }^{*} \text { or diminish }\right.\right. \\
\left.\text { output }{ }^{*}\right) . t w, k w .\end{array}$ & 12569 \\
\hline 15 & $\left(\left(\right.\right.$ low $^{*}$ or diminish* or decreas ${ }^{*}$ or declin* or reduc* or negligibl*) adj output $\left.{ }^{*}\right) . \mathrm{tw}, \mathrm{kw}$. & 2964 \\
\hline 16 & cardiac output low.tw,kw,ot. & 105 \\
\hline 17 & (LCOS or COS or LCO).tw,ot,kw. & 20242 \\
\hline 18 & ((instab* or unstab*) adj1 h?emodyn*).tw,kw. & 12677 \\
\hline 19 & or/12-18 [shock, low CO] & 81903 \\
\hline 20 & 11 and $19[\mathrm{II}=\mathrm{MI}+\mathrm{CO}]$ & 10001 \\
\hline 21 & 8 or 20 [I II] & 38501 \\
\hline 22 & $\begin{array}{l}\text { (book or editorial).pt. or book/ or editorial/ or ((("review" or letter).pt. or "review"/ or letter/) not } \\
\text { (meta analysis/ or "systematic review"/ or clinical study/ or case control study/ or exp controlled } \\
\text { clinical trial/ or controlled study/ or intervention study/ or longitudinal study/ or major clinical } \\
\text { study/ or prospective study/ or retrospective study/ or cohort analysis/ or (systematic adj2 } \\
\text { (literature or review)).tw,ot,kw.)) }\end{array}$ & 3896039 \\
\hline 23 & $\begin{array}{l}\text { ((animal/ or animal experiment/ or animal model/ or nonhuman/) not human/) or (porcine or } \\
\text { piglet or pig or pigs or rat or rats or dogs or dog or canine).ti. or ph?eochrom*.mp. }\end{array}$ & 6420601 \\
\hline 24 & 22 or 23 & 10059750 \\
\hline 25 & 21 not 24 [I II - humans not editorials, reviews] & 30861 \\
\hline 26 & *inotropic agent/ or inotropic agent/ae, ct, cb, cm, dt & 6390 \\
\hline 27 & ${ }^{*}$ cardiotonic agent/ or cardiotonic agent/ae, ct, cb, cm, dt & 2726 \\
\hline 28 & catecholamine/ae, ct, cb, cm, dt & 1671 \\
\hline 29 & (cardiotonic ${ }^{*}$ or inopressor* or inodilator*).tw,ot,kw. & 3739 \\
\hline 30 & 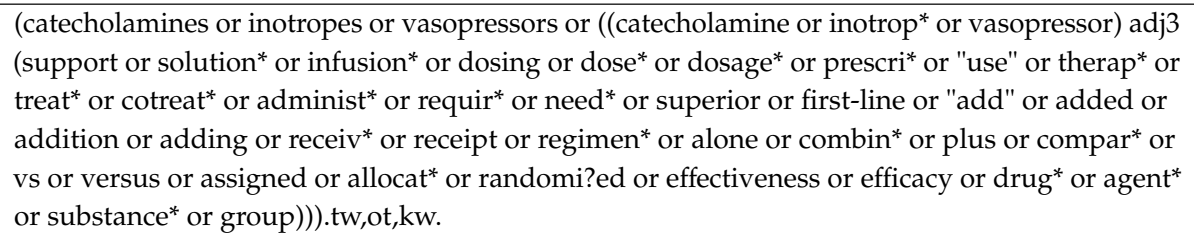 & 74053 \\
\hline 31 & dopamine/ not (dopamine/ec not dopamine/ae, cb, cm, dt) & 80557 \\
\hline 32 & (dopamin* or hydroxytyramin* or Intropin*).tw,ot,kw. & 189228 \\
\hline 33 & dobutamine/ not (dobutamine/ec not dobutamine/ae, cb, cm, dt) & 23435 \\
\hline 34 & dobutamin*.tw,ot,kw. & 12411 \\
\hline 35 & noradrenalin/ not (noradrenalin/ec not noradrenalin/ae, cb, cm, dt) & 114540 \\
\hline 36 & (norepinephrin* or noradrenalin*).tw,ot,kw. & 120459 \\
\hline 37 & adrenalin/ not (adrenalin/ec not adrenalin/ae, cb, cm, dt) & 111164 \\
\hline 38 & (epinephrin* or adrenalin*).tw,ot,kw. & 83979 \\
\hline 39 & milrinone/ & 7278 \\
\hline 40 & milrinon*.tw,ot,kw. & 2706 \\
\hline
\end{tabular}




\begin{tabular}{|l|l|l|}
\hline$\#$ & Searches & Results \\
\hline 41 & vasopressin/ not (vasopressin/ec not vasopressin/ad, cb, cm, dt) & 29150 \\
\hline 42 & vasopressin*.tw,ot,kw. & 41607 \\
\hline 43 & simendan/ & 106 \\
\hline 44 & $($ simendan or levosimend*).tw,ot,kw. & 2165 \\
\hline $\mathbf{4 5}$ & or/26-44 [drugs] & $\mathbf{5 4 9 6 4 6}$ \\
\hline $\mathbf{4 6}$ & $\mathbf{2 5}$ and $\mathbf{4 5}$ [total] & $\mathbf{5 7 2 1}$ \\
\hline $\mathbf{4 7}$ & remove duplicates from $\mathbf{4 6}[$ [total hits -deduplicated] & $\mathbf{5 6 4 0}$ \\
\hline 48 & (embase or elsevier or canadian).cr. & 26116001 \\
\hline $\mathbf{4 9}$ & $\mathbf{4 7}$ and $\mathbf{4 8}[$ EMBASE records only] & $\mathbf{5 2 6 1}$ \\
\hline
\end{tabular}

\section{CENTRAL}

\begin{tabular}{|c|c|c|}
\hline ID & Search & Hits \\
\hline$\# 1$ & (cardiogen* near/9 shock*):ti,ab,kw & 914 \\
\hline \#2 & (circulator* near/3 shock*):ti,ab,kw & 36 \\
\hline \#3 & $\left(\right.$ coron$^{*}$ NEXT shock*):ti,ab,kw & 0 \\
\hline$\# 4$ & (acute NEXT circulatory NEXT fail*):ti,ab,kw & 14 \\
\hline$\# 5$ & $\begin{array}{l}\text { ((undifferent* or undiagnos* or different or various or variety or type or types or kind or kinds } \\
\text { or forms or states or etiologies) near/2 shock*):ti,ab not (heat NEXT shock*):ti,ab }\end{array}$ & 82 \\
\hline$\# 6$ & $\# 1$ or \#2 or \#3 or \#4 or \#5 & 1036 \\
\hline \#7 & 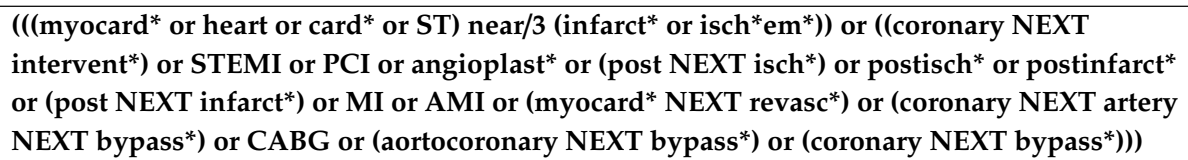 & 57969 \\
\hline$\# 8$ & $\begin{array}{l}\text { shock:ti,kw not (septic or sepsis or bacter*em* or infect* or endotoxin* or (heat NEXT shock) or } \\
\text { HSP* or anaphyl* or allergic or vasodilat* or osmotic or h*emorr* or bleeding or toxic or } \\
\text { neurogen* or burn* or (shock NEXT wave) or (shock NEXT resistant) or hypovolemic or (hypo } \\
\text { NEXT volemic) or electroconvuls* or (distributive NEXT shock*)):ti }\end{array}$ & 2559 \\
\hline \#9 & $\begin{array}{l}\left(\left(\text { low }^{*} \text { or diminish }\right.\right. \\
\text { output } \text { or decreas } \\
\text { oR }(\text { heart } \text { NEXT declin* output }))): t i, a b, k w\end{array}$ & 1094 \\
\hline$\# 10$ & $\left(\left(\right.\right.$ low $^{*}$ or diminish ${ }^{*}$ or decreas ${ }^{*}$ or declin* or reduc $^{*}$ or negligibl $\left.{ }^{*}\right)$ next output $\left.{ }^{*}\right): \mathrm{ti}, \mathrm{ab}, \mathrm{kw}$ & 138 \\
\hline$\# 11$ & (LCOS or COS or LCO):ti,ab,kw & 312 \\
\hline$\# 12$ & $\left(\left(\right.\right.$ instab* or unstab*) near $/ 1 \mathrm{~h}^{*}$ emodyn $\left.{ }^{*}\right): \mathrm{ti}, \mathrm{ab}, \mathrm{kw}$ & 633 \\
\hline \#13 & $\# 8$ or \#9 or \#10 \#11 or \#12 & 4238 \\
\hline$\# 14$ & $\# 7$ and \#13 & 1078 \\
\hline$\# 15$ & $\# 6$ or $\# 14$ & 1595 \\
\hline$\# 16$ & $\begin{array}{l}\text { (cardiotonic* or inopressor* or inodilator* or dopamin* or hydroxytyramin* or Intropin* or } \\
\text { dobutamin* or norepinephrin* or noradrenalin* or epinephrin* or adrenalin* or milrinon* or } \\
\left.\text { vasopressin* or simendan or levosimend }{ }^{*}\right): \mathrm{ti}, \mathrm{ab}, \mathrm{kw}\end{array}$ & 22220 \\
\hline$\# 17$ & $\begin{array}{l}\text { (catecholamines or inotropes or vasopressors or ((catecholamine or inotrop* or vasopressor) } \\
\text { near/3 (support or solution* or infusion* or dosing or dose* or dosage* or prescri* or "use" or } \\
\text { therap* or treat* or cotreat* or administ* or requir* or need* or superior or (first NEXT line) or } \\
\text { "add" or added or addition or adding or receiv* or receipt or regimen* or alone or combin* or } \\
\text { plus or compar* or vs or versus or assigned or allocat* or randomi*ed or effectiveness or efficacy } \\
\text { or drug* or agent* or substance }{ }^{*} \text { or group))):ti,ab,kw }\end{array}$ & 4646 \\
\hline \#18 & $\# 16$ or \#17 & 24628 \\
\hline$\# 19$ & $\# 15$ and \#18 & 277 \\
\hline
\end{tabular}

\section{References}

1. Vallabhajosyula, S.; Dunlay, S.M.; Prasad, A.; Kashani, K.; Sakhuja, A.; Gersh, B.J.; Jaffe, A.S.; Holmes, D.R., Jr.; Barsness, G.W. Acute noncardiac organ failure in acute myocardial infarction with cardiogenic shock. J. Am. Coll. Cardiol. 2019, 73, 1781-1791. [CrossRef] [PubMed]

2. Wayangankar, S.A.; Bangalore, S.; McCoy, L.A.; Ineid, H.; Latif, F.; Karrowni, W.; Charitakis, K.; Feldman, D.N.; Dakik, H.A.; Mauri, L.; et al. Temporal trends and outcomes of patients undergoing percutaneous coronary interventions for cardiogenic shock in the setting of acute myocardial infarction: A report from the CathPCI registry. JACC Cardiovasc. Interv. 2016, 9, 341-351. [CrossRef] 
3. Reynolds, H.R.; Hochman, J.S. Cardiogenic shock: Current concepts and improving outcomes. Circulation 2008, 117, 686-697. [CrossRef]

4. $\quad$ van Diepen, S.; Katz, J.N.; Albert, N.M.; Henry, T.D.; Jacobs, A.K.; Kapur, N.K.; Kilic, A.; Menon, V.; Ohman, E.M.; Sweitzer, N.K.; et al. Contemporary management of cardiogenic shock: A scientific statement from the american heart association. Circulation 2017, 136, e232-e268. [CrossRef]

5. Ibanez, B.; James, S.; Agewall, S.; Antunes, M.J.; Bucciarelli-Ducci, C.; Bueno, H.; Caforio, A.L.P.; Crea, F.; Goudevenos, J.A.; Halvorsen, S.; et al. 2017 ESC guidelines for the management of acute myocardial infarction in patients presenting with ST-segment elevation: The task force for the management of acute myocardial infarction in patients presenting with ST-segment elevation of the European Society of Cardiology (ESC). Eur. Heart J. 2017, 39, 119-177.

6. Berg, D.D.; Bohula, E.A.; Van Diepen, S.; Katz, J.N.; Alviar, C.L.; Baird-Zars, V.M.; Barnett, C.F.; Barsness, G.W.; Burke, J.A.; Cremer, P.C.; et al. Epidemiology of Shock in Contemporary Cardiac Intensive Care Units. Circ. Cardiovasc. Qual. Outcomes 2019, 12, e005618. [CrossRef]

7. Goldberg, R.J.; Samad, N.A.; Yarzebski, J.; Gurwitz, J.; Bigelow, C.; Gore, J.M. Temporal trends in cardiogenic shock complicating acute myocardial infarction. N. Engl. J. Med. 1999, 340, 1162-1168. [CrossRef]

8. Hochman, J.S.; Sleeper, L.A.; Webb, J.G.; Sanborn, T.A.A.; White, H.D.; Talley, J.D.; Buller, C.E.; Jacobs, A.K.; Slater, J.N.; Col, J.; et al. Early revascularization in acute myocardial infarction complicated by cardiogenic shock. SHOCK Investigators. Should we emergently revascularize occluded coronaries for cardiogenic shock. N. Engl. J. Med. 1999, 341, 625-634. [CrossRef]

9. Overgaard, C.B.; Dzavik, V. Inotropes and vasopressors: Review of physiology and clinical use in cardiovascular disease. Circulation 2008, 118, 1047-1056. [CrossRef] [PubMed]

10. Moher, D.; Liberati, A.; Tetzlaff, J.; Altman, D.G. Preferred reporting items for systematic reviews and meta-analyses: The PRISMA statement. PLoS Med. 2009, 6, e1000097. [CrossRef] [PubMed]

11. Higgins, J.P.; Altman, D.G.; Gotzsche, P.C.; Juni, P.; Moher, D.; Oxman, A.D.; Savovic, J.; Schulz, K.F.; Weeks, L.; Sterne, J.A. The cochrane collaboration's tool for assessing risk of bias in randomised trials. BMJ (Clinical Research Ed) 2011, 343, d5928. [CrossRef]

12. Stang, A. Critical evaluation of the Newcastle-Ottawa scale for the assessment of the quality of nonrandomized studies in meta-analyses. Eur. J. Epidemiol. 2010, 25, 603-605. [CrossRef] [PubMed]

13. Balshem, H.; Helfand, M.; Schünemann, H.J.; Oxman, A.D.; Kunz, R.; Brozek, J.; Vist, G.E.; Falck-Ytter, Y.; Meerpohl, J.; Norris, S.; et al. GRADE guidelines: 3. Rating the quality of evidence. J. Clin. Epidemiol. 2011, 64, 401-406. [CrossRef] [PubMed]

14. Levy, B.; Clere-Jehl, R.; Legras, A.; Morichau-Beauchant, T.; Leone, M.; Frederique, G.; Quenot, J.P.; Kimmoun, A.; Cariou, A.; Lassus, J.; et al. Epinephrine versus norepinephrine for cardiogenic shock after acute myocardial infarction. J. Am. Coll. Cardiol. 2018, 72, 173-182. [CrossRef] [PubMed]

15. Myburgh, J.A.; Higgins, A.; Jovanovska, A.; Lipman, J.; Ramakrishnan, N.; Santamaria, J. Investigators CATS: A comparison of epinephrine and norepinephrine in critically ill patients. Intensive Care Med. 2008, 34, 2226-2234. [CrossRef]

16. De Backer, D.; Biston, P.; Devriendt, J.; Madl, C.; Chochrad, D.; Aldecoa, C.; Brasseur, A.; Defrance, P.; Gottignies, P.; Vincent, J.L.; et al. Comparison of dopamine and norepinephrine in the treatment of shock. N. Engl. J. Med. 2010, 362, 779-789. [CrossRef]

17. Samimi-Fard, S.; Garcia-Gonzalez, M.J.; Dominguez-Rodriguez, A.; Abreu-Gonzalez, P. Effects of levosimendan versus dobutamine on long-term survival of patients with cardiogenic shock after primary coronary angioplasty. Int. J. Cardiol. 2008, 127, 284-287. [CrossRef]

18. Husebye, T.; Eritsland, J.; Muller, C.; Sandvik, L.; Arnesen, H.; Seljeflot, I.; Mangschau, A.; Bjornerheim, R.; Andersen, G.O. Levosimendan in acute heart failure following primary percutaneous coronary intervention-treated acute ST-elevation myocardial infarction. Results from the LEAF trial: A randomized, placebo-controlled study. Eur J. Heart Fail. 2013, 15, 565-572. [CrossRef]

19. Fuhrmann, J.T.; Schmeisser, A. Levosimendan is superior to enoximone in refractory cardiogenic shock complicating acute myocardial infarction. Crit. Care Med. 2009, 37, 2678-2679. [CrossRef]

20. Tarvasmaki, T.; Lassus, J.; Varpula, M.; Sionis, A.; Sund, R.; Kober, L.; Spinar, J.; Parissis, J.; Banaszewski, M.; Silva Cardoso, J.; et al. Current real-life use of vasopressors and inotropes in cardiogenic shock - adrenaline use is associated with excess organ injury and mortality. Crit. Care (London, England) 2016, 20, 208. [CrossRef] 
21. Cronin, R.F.; Moore, S.; Marpole, D.G. Shock following myocardial infarction: A clinical survey of 140 cases. Can. Med Assoc. J. 1965, 93, 57-63. [PubMed]

22. Yagi, T.; Tachibana, E.; Ueki, Y.; Sakamoto, K.; Imamura, H.; Miyamoto, T.; Takahashi, H.; Hanada, H.; Yonemoto, N.; Nagao, K.; et al. The effect of vasopressor agents in the treatment of cardiovascular shock. Circulation 2015, 132 (Suppl. 3), A13004.

23. Lewis, T.C.; Aberle, C.; Altshuler, D.; Piper, G.L.; Papadopoulos, J. Comparative effectiveness and safety between milrinone or dobutamine as initial inotrope therapy in cardiogenic shock. J. Cardiovasc. Pharmacol. Ther. 2018. [CrossRef] [PubMed]

24. Vally, S.; Ferdynus, C.; Persichini, R.; Bouchet, B.; Braunberger, E.; Lo Pinto, H.; Martinet, O.; Vandroux, D.; Aujoulat, T.; Allyn, J.; et al. Impact of levosimendan on weaning from peripheral venoarterial extracorporeal membrane oxygenation in intensive care unit. Ann. Intensive Care 2019, 9, 24. [CrossRef]

25. Affronti, A.; di Bella, I.; Carino, D.; Ragni, T. Levosimendan may improve weaning outcomes in venoarterial ECMO patients. ASAIO J. 2013, 59, 554-557. [CrossRef]

26. Omerovic, E.; Ramunddal, T.; Albertsson, P.; Holmberg, M.; Hallgren, P.; Boren, J.; Grip, L.; Matejka, G. Levosimendan neither improves nor worsens mortality in patients with cardiogenic shock due to ST-elevation myocardial infarction. Vasc. Health Risk Manag. 2010, 6, 657-663. [CrossRef]

27. Caetano, F.; Almeida, I.; Silva, J.; Botelho, A.; Mota, P.; Leitao Marques, A. Cardiogenic shock in acute myocardial infarction: Still looking for the best inotrope. Eur. Heart J. Acute Cardiovasc. Care 2012, 1, $28-29$.

28. Christoph, A.; Prondzinsky, R.; Russ, M.; Janusch, M.; Schlitt, A.; Lemm, H.; Reith, S.; Werdan, K.; Buerke, M. Early and sustained haemodynamic improvement with levosimendan compared to intraaortic balloon counterpulsation (IABP) in cardiogenic shock complicating acute myocardial infarction. Acute Card. Care 2008, 10, 49-57. [CrossRef]

29. Katsytadze, I.; Amosova, E.; Prudkyi, I.; Bogomolets, A.K.O. Long term effects of Levosimendan therapy in patients with cardiogenic shock. Resuscitation 2013, 84, S11. [CrossRef]

30. El Mokhtari, N.E.; Arlt, A.; Meissner, A.; Lins, M. Inotropic therapy for cardiac low output syndrome: Comparison of hemodynamic effects of dopamine/dobutamine versus dopamine/dopexamine. Eur. J. Med Res. 2007, 12, 563-567. [CrossRef]

31. Moulopoulos, S.D.; Stamateolopoulos, S.F.; Nanas, J.N.; Kontoyannis, D.A.; Nanas, S.N. Effect of protracted dobutamine infusion on survival of patients in cardiogenic shock treated with intraaortic balloon pumping. Chest 1993, 103, 248-252. [CrossRef] [PubMed]

32. Andriange, M.; Calay, G.; Gach, J.; Lisin, N. Shock states during myocardial infarct: Treatment of cardiogenic shock with dopamine. Acta Clinica Belgica 1971, 26, 249-261. [CrossRef] [PubMed]

33. Schumann, J.; Henrich, E.C.; Strobl, H.; Prondzinsky, R.; Weiche, S.; Thiele, H.; Werdan, K.; Frantz, S.; Unverzagt, S. Inotropic agents and vasodilator strategies for the treatment of cardiogenic shock or low cardiac output syndrome. Cochrane Database Syst. Rev. 2018. [CrossRef] [PubMed]

34. Gamper, G.; Havel, C.; Arrich, J.; Losert, H.; Pace, N.L.; Mullner, M.; Herkner, H. Vasopressors for hypotensive shock. Cochrane Database Syst. Rev. 2016. [CrossRef]

35. Lamontagne, F.; Richards-Belle, A.; Thomas, K.; Harrison, D.A.; Sadique, M.Z.; Grieve, R.D.; Camsooksai, J.; Darnell, R.; Gordon, A.C.; Henry, D.; et al. Effect of reduced exposure to vasopressors on 90-Day mortality in older critically ill patients with Vasodilatory hypotension: A randomized clinical trial. JAMA 2020, 323, 938-949. [CrossRef]

36. Ong, M.E.H.; Tiah, L.; Leong, B.S.-H.; Tan, E.C.C.; Ong, V.Y.K.; Tan, E.A.T.; Poh, B.Y.; Pek, P.P.; Chen, Y. A randomised, double-blind, multi-centre trial comparing vasopressin and adrenaline in patients with cardiac arrest presenting to or in the Emergency Department. Resuscitation 2012, 83, 953-960. [CrossRef]

37. Perkins, G.D.; Ji, C.; Deakin, C.D.; Quinn, T.; Nolan, J.P.; Scomparin, C.; Regan, S.; Long, J.; Slowther, A.; Pocock, H.; et al. A randomized trial of epinephrine in out-of-hospital cardiac arrest. N. Engl. J. Med. 2018, 379, 711-721. [CrossRef]

38. Olasveengen, T.M.; Sunde, K.; Brunborg, C.; Thowsen, J.; Steen, P.A.; Wik, L. Intravenous drug administration during out-of-hospital cardiac arrest: A randomized trial. JAMA 2009, 302, 2222-2229. [CrossRef]

(C) 2020 by the authors. Licensee MDPI, Basel, Switzerland. This article is an open access article distributed under the terms and conditions of the Creative Commons Attribution (CC BY) license (http://creativecommons.org/licenses/by/4.0/). 